Article

\title{
Study of System Integral Energy Efficiency of a Hybrid Pneumatic Power System
}

\author{
Po-Tuan Chen ${ }^{1,2} \oplus$, Duong Dinh Nghia ${ }^{3}$, Cheng-Jung Yang ${ }^{4, *}$ and K. David Huang ${ }^{3, *}$ \\ 1 Center for Condensed Matter Sciences, National Taiwan University, Taipei 10617, Taiwan; \\ r92222019@ntu.edu.tw \\ 2 Center of Atomic Initiative for New Materials, National Taiwan University, Taipei 10617, Taiwan \\ 3 Department of Vehicle Engineering, National Taipei University of Technology, Taipei 10608, Taiwan; \\ duongdinhnghia88@gmail.com \\ 4 Department of Mechanical Engineering, National Pingtung University of Science and Technology, Pingtung \\ 91201, Taiwan \\ * Correspondence: cjyang@mail.npust.edu.tw (C.-J.Y.); kdavidh@ntut.edu.tw (K.D.H.); \\ Tel.: +886-8-7703202 (ext. 7012) (C.-J.Y.); +886-2-2771-2171 (ext. 3676) (K.D.H.)
}

Received: 14 April 2019; Accepted: 31 May 2019; Published: 6 June 2019

check for updates

\begin{abstract}
Currently, in the field of vehicle engineering, researchers are focused on finding a new type of high-efficiency vehicle. Based on the conventional powertrain system, the hybrid pneumatic power system (HPPS) is a type of hybrid system that focuses on compressed air power instead of the electrochemical energy conversion of a battery. This study concentrates on the integral efficiency of the HPPS. The HPPS was operated under different conditions of internal combustion engine speed, fuel consumption, compressor speed, pressure in air tank, cross-sectional area, and air motor efficiency. Based on this, the best operating condition of the HPPS was defined, and the integral efficiency of the HPPS was measured under this condition. The experimental results show that the system integral efficiency can reach up to $45.3 \%$. It is higher than $28 \%$ when using individual internal combustion engines. In addition, the HPPS could reduce fuel consumption by $38 \%$ during its best performance.
\end{abstract}

Keywords: vehicle engineering; hybrid pneumatic power system; hybrid system; fuel consumption

\section{Introduction}

In recent years, in addition to the technical advancement of the internal combustion engine (ICE), a significant amount of research effort has been given to designing a new type of vehicle that utilizes the ICE, called the hybrid electric vehicle (HEV); it uses both an electric motor and an ICE to generate power for propulsion. The major advantages of the HEV are increased energy efficiency and a reduced greenhouse effect compared with conventional vehicles. The new technology has overcome several challenges of HEV development, such as system integration [1], difficulty in recharging the battery in a short time [2,3], matching of the best power conditions [4], and plausible alternative energy sources [5-7]. However, product design and product sustainability are crucial to the success of HEVs in the future [8-10]. Combined with reductions in energy and environmental pollution for future use, air-powered vehicles present several superiorities [11,12]. First, only air is emitted during operation; therefore, production of compressed air appears to be the only possible pollution source. Also, the cost of air power is much lower than that of fossil fuels, such as in the case of electric, battery, and fuel-cell vehicles. Finally, the container for the compressed air can be designed such that it can be assembled and disassembled conveniently. The vehicle can be refilled with power faster when compared to electric vehicles in particular. Dimitrova and Maréchal demonstrated that the pneumatic driveline was up to $67 \%$ lighter than the lightest competing hybrids, and that fuel consumption could be reduced from $35 \%$ to $30 \%$ [13]. 
The concept of the pneumatic car was proposed in the early 20th century. Broderick [14] obtained a patent named "Combined internal combustion and compressed air engine". In this concept, the compressed air is used to ignite and start an ICE or vehicle brakes. Compressed air is produced from two of four engine cylinders while the other two cylinders perform their typical functions. The concept of applying a multicylinder engine to generate compressed air was proposed by Ochel et al. [15]. This concept is similar to that of Broderick's patent. The only difference is that Ochel's concept was intended for driving pneumatic tools such as spray guns and drill hammers. Brown [16] filed for a patent that utilized a compressor with an electric motor to generate compressed air to drive an air engine. Ueno [17] proposed an invention wherein ICE cylinders were used for compressing air and subsequently allow this air to drive a vehicle. Ueno's invention could also perform regenerative braking, which was not feasible in Broderick's invention. Moyers [18] defined the pneumatic hybrid, which is currently available. He utilized supercharging to store gas into a pressure tank such that the pressure inside the tank was greater than the outside environment.

In 1998, Motor Development International, SA (MDI), first introduced air vehicles for commercial purposes. Currently, MDI can support single- to six-seater minibuses. In collaboration with MDI, Tata Motors released an air-powered vehicle named AIRPOD in 2012. The Korean company Energine created a pneumatic hybrid electric vehicle in 2005. The engine of this vehicle operated with an electric motor to generate the power source. The Lucksky Group from China displayed an airbus at the Beijing International High-Tech Expo in 2015. Additionally, several research institutes and car companies worldwide have recently focused on air-powered vehicle development [19].

In addition to purely air-powered vehicles, a part of the research is related to the combination of the systems with conventional internal combustion engine. Fang et al. showed that the pneumatic power system uses heat of cooling water to optimize the performance of air engine. It can increase power by $38.22 \%$ and efficiency from $26.18 \%$ to $41.22 \%$, and save $50 \%$ of fan power [20]. Sasa Trajkovic et al. showed that this research focuses on using waste power when a vehicle is decelerated. After that, this power will drive the wheel when the vehicle is accelerated. The results show that this solution can reduce $58 \%$ fuel consumption [21]. A system of hybrid pneumatic drivelines was developed by EXELIS [22]. The system exhibits enhanced fuel efficiency and reduced air pollution than hydraulic and electric hybrids. Huang et al. $[23,24]$ designed a hybrid pneumatic power system that combined exhaust flow and compressed air flow. This concept was adopted from the ICE to be in parallel with the air compressor such that the air can be directly compressed into a storage tank for energy storage. Additionally, high-temperature waste gas from the ICE is merged with the compressed air using a merger pipe to improve the output flow power.

Energy management is emphasized in this study to obtain the highest system integral efficiency of a hybrid pneumatic power system (HPPS). In our HPPS, the crankshaft of the ICE is connected to the air compressor. The air compressor operates at many conditions of ICE, such as power and speed at the outlet ICE. By controlling the ICE, the characteristic of compressed air flow at the outlet compressor will change. It means that an ICE, a compressor, and an air tank have a binding relationship. Finally, the integral efficiency of the HPPS is measured at the best operating condition of the HPPS.

\section{Materials and Methods}

\subsection{Experimental Setup of Our HPPS}

The framework of our HPPS is shown in Figure 1. This system contains an internal combustion engine (ICE) (1) that is used to drive an air compressor (2), a one-way valve (3) that controls the air flow to a high-pressure air storage tank (4), a control valve (5) that adjusts air flow to a merger pipe (6), and an air motor (7) that obtains air flow from both the ICE and air storage tank. The torque sensor (8), pressure sensor $(\mathrm{P})$, flow sensor $(\mathrm{F})$, and temperature sensor $(\mathrm{T})$ are connected with an $\mathrm{A} / \mathrm{D}$ transformer and a computer (11) to measure the system specification. 


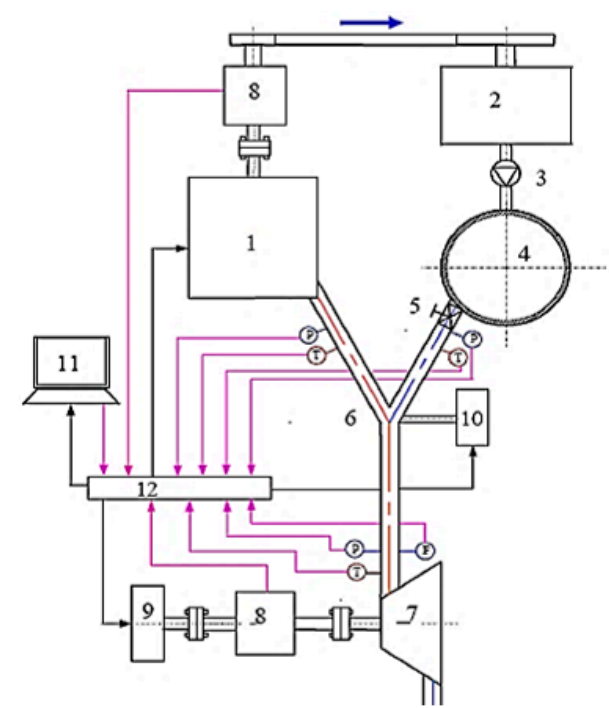
(1) ICE
(6) Merger pipe
(11) Computer
(2) Air compressor
(7) Air motor
(12) A/D transformer

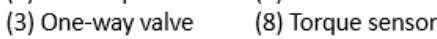
(P) Pressure sensor
(4) Air storage tank
(9) Load cell
(T) Temperature sensor
(5) Control valve
(10) Electric motor
(F) Flow sensor

Figure 1. The framework of our hybrid pneumatic power system (HPPS).

The ICE drives a compressor to charge an air tank. The compressed air flow and exhaust flow are then mixed at merger pipe. The merger flow is controlled by a stepper motor, which adjusts the merger position to create a venture geometry. By combination of both flows, the merger pipe enhances the kinetic energy of the compressed air flow. At the output of the merger pipe, with high pressure and temperature, the merger flow drives an air motor. This not only saves the chemical energy from the fuel, but also reduces air pollution.

\subsubsection{ICE}

The specifications of the ICE (SYM Corporation) are one cylinder, four strokes, and 125 cc exhaust volume. The maximum output is $12 \mathrm{PS} / 7500 \mathrm{rpm}$, the maximum torque is $1.2 \mathrm{~kg} \cdot \mathrm{m} / 6500 \mathrm{rpm}$, the fuel is gasoline, the fuel feed system is a carburetor, and the cooling mode is air cooled. It reaches the sweet spot of brake specific fuel consumption (BSFC) by $5000 \mathrm{rpm}$ at the free-load condition. Therefore, the air compressor can utilize a stable load after the ICE is ignited, thereby maintaining the ICE operating at a fixed rotational speed.

\subsubsection{Air Compressor and Air Tank}

The compressor used in our system is an oil-injected, rotary-screw compressor. It has a power range of up to $11 \mathrm{~kW}$, maximum acceleration of $8500 \mathrm{rpm}$, maximum flow rate of $1.2 \mathrm{~m}^{3} / \mathrm{m}$, and functions under a pressure of 15 bar. An air storage tank is used for storing compressed air to maintain a stable compressed flow, reduce pressure fluctuations, and allow for the braking components to perform smoothly. In our HPPS, the tank capacity is $110 \mathrm{~L}$, with compressed air pressure that can reach up to 15 bar.

\subsubsection{Energy Merger Pipe}

The major advantage of the HPPS is the energy merger pipe, which has been evaluated and analyzed thoroughly in previous studies [24]. In this pipe, the exhaust pipe diameter, compressed air pipe diameter, and common pipe diameter were all kept at $34 \mathrm{~mm}$. The angle between the compressed air pipe and exhaust pipe was set to $30^{\circ}$. The role of the energy merger pipe is important owing to its mixing capability that is responsible for generating merger flow. In particular, the cross-sectional area at the merging region of the pipe directly affects the recycling efficiency of the exhaust-gas energy. 
From Ref. [25], information on high-pressure compressed airflow and high-temperature exhaust-gas flow under different cross-sectional areas can been found.

\subsubsection{Air Motor}

The function of an air motor is to convert fluid power to drive the shaft. The pressure and flow rate are converted into torque and speed, respectively. An air motor (T30-M, TDI Tech Development) was utilized in our HPPS, whose maximum power was approximately $35 \mathrm{PS} / 26 \mathrm{~kW}$, maximum inlet pressure was approximately $150 \mathrm{Psig}$, and the maximum speed was higher than $4000 \mathrm{rpm}$.

\subsection{Data Acquisition}

To run the system and to measure the signal from the sensors, this study used a data collector (USB-6218, National Instruments) and LabVIEW software [26].

\subsection{Efficiency}

\subsubsection{ICE Heat Efficiency}

Thermal efficiency is defined as the percentage of energy that can be transferred from combustion to mechanical work. The base value of combustion efficiency ranged from 0.95 to 0.98 when the engine was operating. For one engine cycle in one cylinder, the added heat [27] is calculated as follows:

$$
Q_{i n}=m_{f} Q_{H V} \eta_{c}
$$

For steady state:

$$
\dot{Q}_{i n}=\dot{m}_{f} Q_{H V} \eta_{c}
$$

and the thermal efficiency is:

$$
\eta_{t}=\frac{W}{Q_{i n}}=\frac{\dot{W}}{\dot{Q}_{i n}}=\frac{\dot{W}}{\dot{m}_{f} Q_{H V} \eta_{c}}=\frac{\eta_{f}}{\eta_{c}}
$$

where $W$ is the work of one cycle, $\dot{W}$ is the power, $m_{f}$ is the mass of fuel of one cycle, and $\dot{m}_{f}$ is the mass flow rate of fuel; the gasoline density is $0.71-0.77 \mathrm{~kg} / \mathrm{L}, Q_{H V}$ is the heating value of fuel: $47.3 \mathrm{MJ} / \mathrm{kg}$, and $\eta_{f}$ is the fuel convention efficiency.

\subsubsection{Compressor Efficiency}

The definition of isentropic efficiency in a compressor is the ratio of work input to the isentropic process, to the work input to the actual process between the same inlet and outlet pressures.

$$
\eta_{C}=\frac{\text { Isentropic compressor work }}{\text { Actual compressor work }}=\frac{W_{s}}{W_{a}}
$$

where $\eta_{C}$ is the isentropic efficiency; $W_{s}$ is the isentropic compressor work; $W_{a}$ is the actual compressor work; $W_{a}$ and $W_{s}$ can be determined from the energy balance of the pumps.

During an enthalpy change, energy associated with the gas flowing through the compressor are negligible. The energy balance of the compressor becomes:

$$
\dot{W}=-\dot{m}\left(\mathrm{~h}_{2}-\mathrm{h}_{1}\right)
$$

The isentropic efficiency of a compressor becomes:

$$
\eta_{c} \cong\left(h_{2 s}-h_{1}\right) /\left(h_{2 a}-h_{1}\right)
$$


In the HPPS, $W_{s}$ equals the output of ICE-W (work of one cycle). $W_{a}$ equals the energy stored in the air tank. This energy can be calculated by the theory of storage thermodynamics. For a process from an initial condition $\mathrm{A}$ to a final condition $\mathrm{B}$, with constant absolute temperature $\mathrm{T}=\mathrm{T}_{\mathrm{A}}=\mathrm{T}_{\mathrm{B}}$. Additionally, if the outside of the container maintains a constant pressure that equals the initial pressure $P_{A}$, the external pressure will reduce the available energy. The equation to calculate the energy stored in an air tank is as follows:

$$
W_{a}=W=P_{A} P_{B} \ln \frac{P_{A}}{P_{B}}+\left(V_{A}-V_{B}\right) P_{A}=P_{A} V_{A} \ln \frac{P_{A}}{P_{B}}+\left(P_{B}-P_{A}\right) V_{B}
$$

where $W$ is the energy stored in the air tank (Watt), $P_{A}$ is the absolute pressure in the air tank $\left(\mathrm{N} / \mathrm{m}^{2}\right)$, $V_{A}$ is the volume of the air tank $\left(\mathrm{m}^{3}\right), P_{B}$ is the absolute pressure at state $\mathrm{B}\left(\mathrm{N} / \mathrm{m}^{2}\right)$, and $V_{B}$ is the volume at state B. $\left(\mathrm{m}^{3}\right)$.

\subsubsection{Air Motor Efficiency}

The inlet and outlet pressures are fixed for an adiabatic turbine in a steady flow process. Therefore, the turbine is an isentropic process between the inlet and outlet pressures under an idealized process. Hence, the ratio of the actual work outlet of the turbine to the work output of the turbine can be defined as the isentropic efficiency, if the turbine is under an isentropic process.

$$
\eta=\frac{\text { Actual turbine work }}{\text { Isentropic turbine work }}=\frac{W_{a t}}{W_{s t}}
$$

The value of $W_{a t}$ and $W_{s t}$ can be acquire form the energy balance of the turbine. Otherwise, the efficiency of the turbine is calculated based on the following equation [24]:

$$
\eta=\frac{\omega T}{m \Delta P}
$$

where $\eta$ is the theoretical efficiency (\%); $\omega$ is angular velocity ( $\mathrm{rad} / \mathrm{s}) ; T$ is the torque (Nm); $\Delta P$ is the pressure difference across the air turbine (bar); and $m$ is the inlet flow rate of the air turbine.

\subsubsection{System Efficiency}

Herein, we present the theoretical calculation of integral efficiency. The ICE efficiency, compressor efficiency, and air motor efficiency have been defined. We apply the Bernoulli equation to the $Y$ junction, and the energy at inlet and outlet of merger pipe is measured as:

$$
Q_{\text {in }}=Q_{\text {loss }}+Q_{\text {out }}
$$

where $Q_{i n}$ is the energy of flow at the merger inlet ( $Q_{1}$ (compressed airflow inlet) and $Q_{2}$ (exhaust-gas flow inlet)); $Q_{\text {out }}$ is the energy of flow at the merger outlet $\left(Q_{3}\right)$; and $Q_{\text {loss }}$ is the energy loses in pipe; we assume that $Q_{\text {loss }}=0$.

Equation (10) becomes:

$$
Q_{1}+Q_{2}=Q_{3}
$$

Base on the energy being released when the fuel is burnt, Equation (11) can eb rewritten as:

$$
\eta_{t} \eta_{C} W+\eta_{\text {exhaust }} W=\mathrm{Q}_{3}
$$

where $\eta_{t}$ denotes the ICE efficiency; $\eta_{C}$ denotes the compressor efficiency; and $\eta_{\text {exhaust }}$ denotes the efficiency loses in the exhaust gas of ICE.

Following the construction of the system (Figure 1), the integral efficiency can be calculated as:

$$
\eta_{t-H P P S} W=\mathrm{Q}_{3} \eta \Leftrightarrow \eta_{t-H P P S} W=\left(\eta_{t} \eta_{C} W+\eta_{\text {exhaust }} W\right) \eta
$$


where $\eta$ denotes the air motor efficiency.

In the HPPS, system efficiency is known as fuel efficiency during operation. It is the efficiency with which the potential energy of the fuel is converted into its kinetic energy. The overall fuel efficiency varies depending on the equipment, especially for fossil fuels in combustion power plants. Fuel economy is the energy efficiency of a particular system in the HPPS, and is related to engine, transmission, and compressor efficiencies. Fuel consumption allows for a more accurate measurement of the HPPS performance, owing to the fact that fuel consumption exhibits a linear relationship whereas fuel economy results in a distorted improvement of efficiency.

Here, we can define the HPPS efficiency:

$$
\eta_{t-H P P S}=\frac{W_{\text {out }}}{Q_{\text {in }} \cdot \eta_{\text {tranmission }}}
$$

where $\eta_{t-H P P S}$ denotes HPPS efficiency and $W_{\text {out }}$ denotes the outlet power of the air motor; $Q_{i n}$ is the energy including fuel consumption; $\eta_{\text {tranmission }}$ is the efficiency of the mechanical setup on the HPPS.

$$
\eta_{\text {tranmission }}=\eta_{\text {chain tranmission }} \eta_{\text {belt tranmission }} \eta_{\text {roller }}
$$

where $\eta_{\text {chain tranmission }}$ is the chain transmission efficiency; $\eta_{\text {belt tranmission }}$ is the belt transmission efficiency; $\eta_{\text {roller }}$ is the efficiency of the roller.

\section{Results}

When our HPPS is running, ICE connects with the compressor to create compressed air. It means the ICE operates with no free load. In this case, the ICE characteristic depends on the volume of the butterfly valve (intake throttle) of ICE. This valve controls the intake flow of the ICE. It will change from $0^{\circ}$ at the closing position to $90^{\circ}$ at the maximum opening position.

Following Figure 1, before taking the data from the HPPS, the ICE was warmed up for $2 \mathrm{~min}$ without connecting to the compressor. When it was warmed up, the ICE was directly connected to the compressor. The compressed air after the compressor was stored in the air tank. Following Ref. [24], the cross-section area was set at an optimal position of approximately $40 \%$ by adjusting the electric motor. The compressed air flow was adjusted by an electric valve.

\subsection{Exhaust Pressure and Temperature of the ICE}

The exhaust pressure was measured by the pressure sensor, in the case of different volumes, in the butterfly valve (intake throttle) of the ICE, as shown in Figure 2. The horizontal axis (load percentage) is the volume of the butterfly valve (intake throttle) of the ICE. It changed from $0^{\circ}$ at the closing position to $90^{\circ}$ at the maximum position. The vertical axis (exhaust pressure) is relative pressure (not including the atmosphere). Figure 2 shows that the exhaust pressure depended on the intake of the ICE and was linear. When the volume was increased from $0 \%$ to $90 \%$, the exhaust pressure rose regularly from 14 to 34 Psig.

The exhaust temperature was measured by the temperature sensor, in the case of different volumes, in the butterfly valve (intake throttle) of the ICE, as shown in Figure 3. The horizontal axis (load percentage) is the volume of the butterfly valve (intake throttle) of the ICE. It changed from $0^{\circ}$ at the closing position to $90^{\circ}$ at the maximum position. The vertical axis shows the exhaust temperature in ${ }^{\circ} \mathrm{C}$. Following Figure 3, we can see that the exhaust temperature increased linearly with the intake throttle of ICE. When the intake valve of the ICE changed from $0 \%$ to $30 \%$, the temperature of the exhaust rose slightly from $100{ }^{\circ} \mathrm{C}$ to $170{ }^{\circ} \mathrm{C}$. After that, from $30 \%$ to $90 \%$ of the volume of intake throttle, the temperature increased from $170{ }^{\circ} \mathrm{C}$ to $450{ }^{\circ} \mathrm{C}$, at a faster rate than before. 


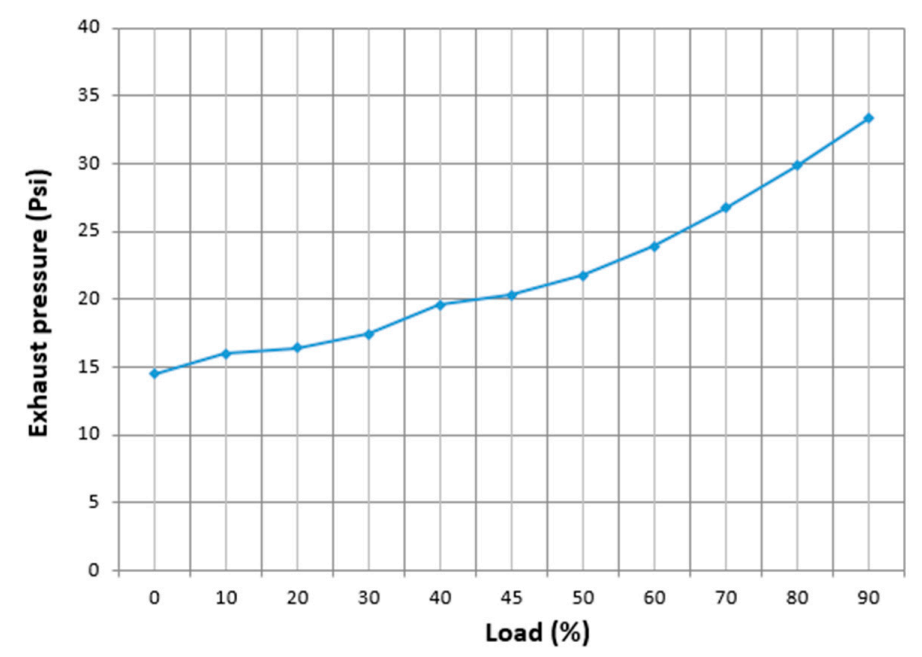

Figure 2. Relationship between \%load and exhaust pressure of ICE.

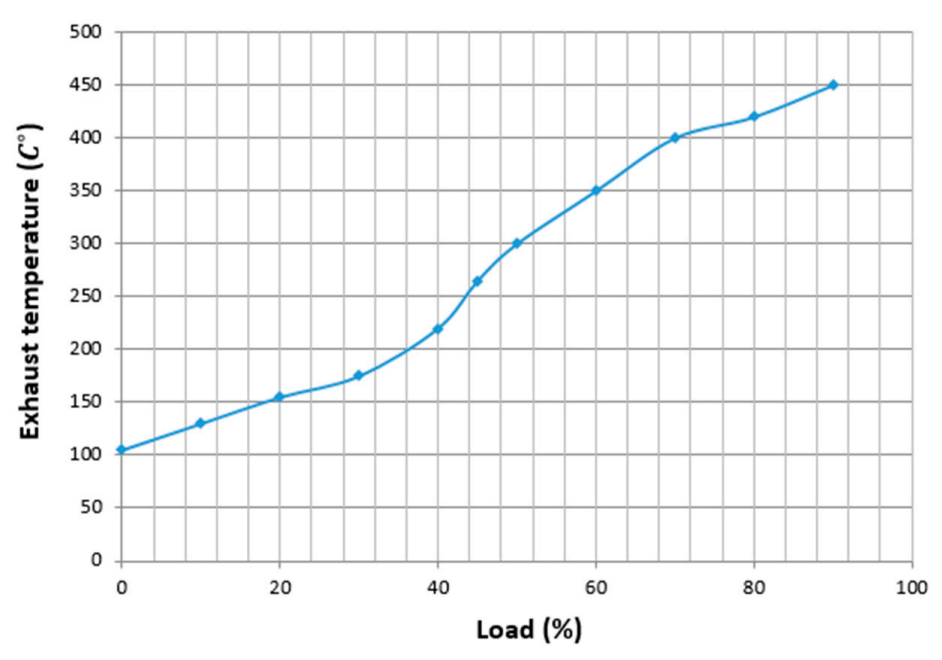

Figure 3. Relationship between \%load and exhaust temperature.

\subsection{Fuel Consumption and Heat Efficiency of ICE}

As the ICE drives the compressor, we recorded fuel consumption following the time and pressure in air tank, at many speeds. The horizontal axis (rpm) is the combustion engine speed at the crank shaft for a period of $1 \mathrm{~min}$. The vertical axis (fuel consumption, $\mathrm{g} / \mathrm{kWh}$ ) is the value of gasoline for which the ICE spent 1 kilowatt in $1 \mathrm{~h}$. Figure 4 estimates a relationship between engine speed and fuel consumption, where the engine speed ranges from 3000 to $4250 \mathrm{rpm}$. It shows clearly that when the engine speed was approximately $3800 \mathrm{rpm}$, the lowest fuel consumption was approximately $316.9 \mathrm{~g}$. At an engine speed of 3000 to $3800 \mathrm{rpm}$, the fuel consumption slightly reduced from 350 to $316.9 \mathrm{~g}$. Moreover, from 3800 to $4500 \mathrm{rpm}$, the fuel consumption was regularly increased from 316.9 to nearly $330 \mathrm{~g}$. From this result, we know that when the ICE drives the compressor, an engine speed of $3500 \mathrm{rpm}$ to $4000 \mathrm{rpm}$ is the best position to conserve fuel.

The heat efficiency of the ICE was measured by the ratio of power at the crank shaft (which is recorded by the torque sensor) and the chemical power of the fuel. The horizontal axis (rpm) is the combustion engine speed at the crank shaft for a period of $1 \mathrm{~min}$. The vertical axis (heat Efficiency) is percentage (\%). Figure 5 shows the relationship between engine speed and heat efficiency; this is important information required to run the ICE. When it drove the compressor, from 3500 to $4000 \mathrm{rpm}$, the ICE had high heat efficiency, from $26 \%$ to $28 \%$. Before and after that, the efficiency was reduced. 


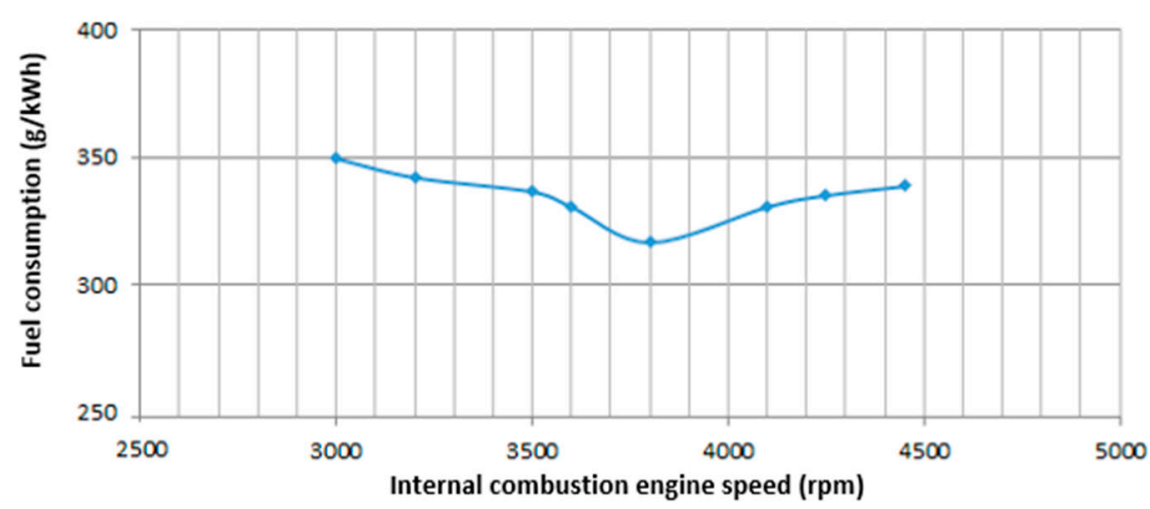

Figure 4. Fuel consumption of combustion engine when it connects with the compressor.

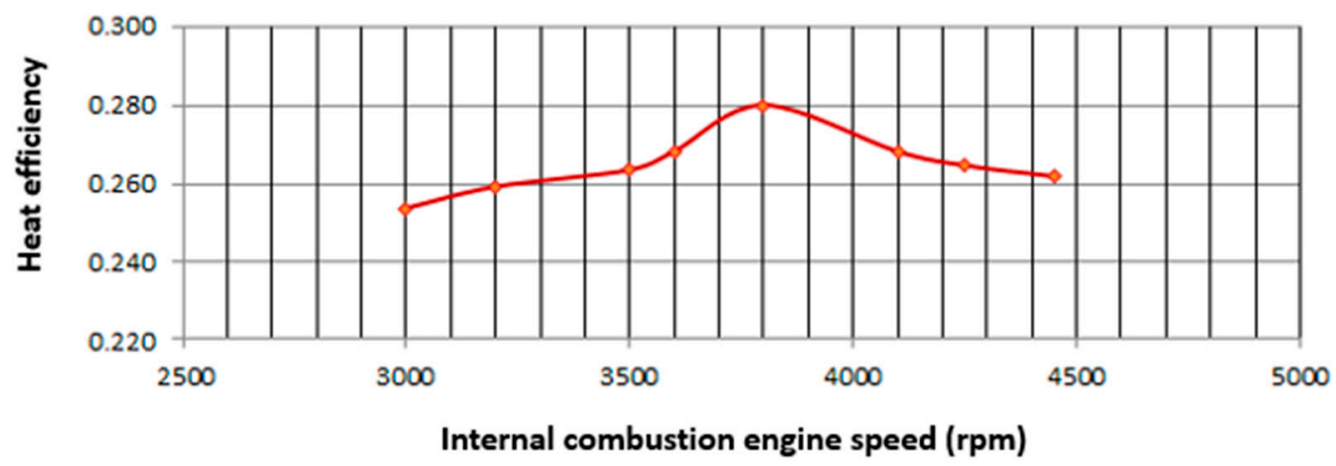

Figure 5. Heat efficiency of combustion engine when it connects with the compressor.

\subsection{Compressor Efficiency and Flow Energy Storing of Air Storage Tank}

The efficiency of the compressor is the ratio of inlet power (at the driver shaft) and power of compressed air (which is stored in the air tank). On our HPPS, the compressor was driven by an ICE. This means that at every speed of the ICE, the compressor will have a corresponding efficiency value. The experimental results in Figure 6 shows that from 3700 to $4250 \mathrm{rpm}$, the compressor had the highest efficiency of approximately $70 \%$. At $<3700 \mathrm{rpm}$, the efficiency of the compressor reduced slightly when the engine speed was decreased. When the ICE speed was higher than $4250 \mathrm{rpm}$, the efficiency of the compressor went down considerably.

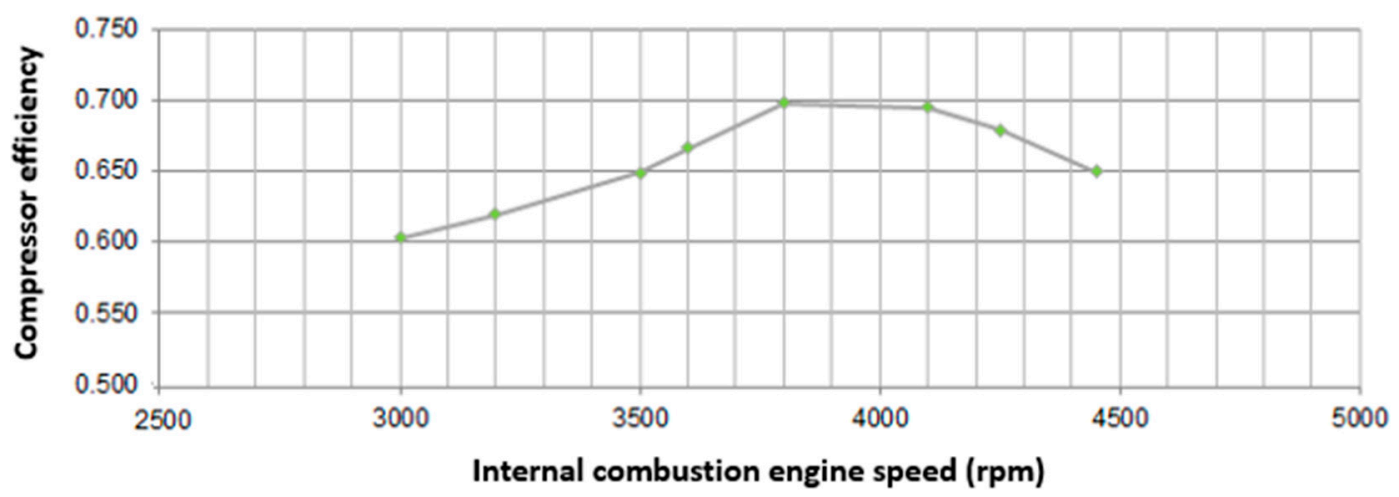

Figure 6. Compressor efficiency when it driven by a combustion engine.

Figure 7 shows the pressure value of the air storage tank at different ICE speeds. When the ICE was operating at a high speed, the energy storage flow of the air storage tank increased rapidly. This is because when the ICE speed increases, the compressed air supplied to the air storage tank by the air compressor increases as well. For instance, the pressure of the air storage tank reached 120 Psig at approximately $150 \mathrm{~s}$ when the ICE speed was $4250 \mathrm{rpm}$. The experimental result indicates that the 
flow energy can be filled quickly into the air storage tank in our HPPS. Additionally, the compressed air flow stored in the air storage tank can be used at all times.

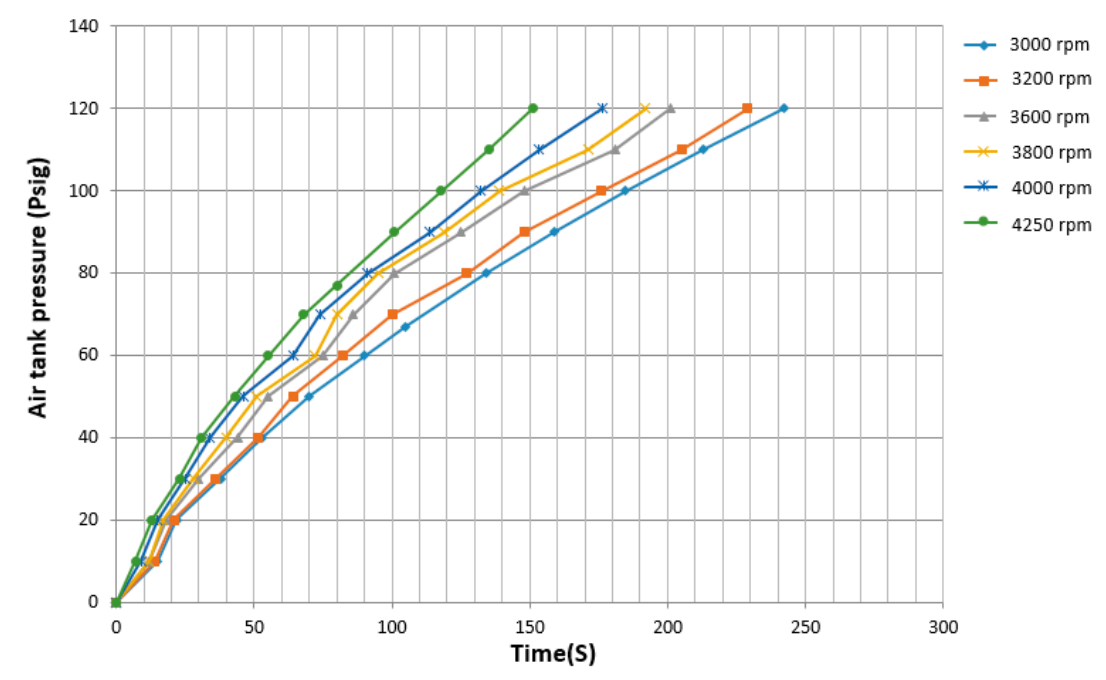

Figure 7. Pressure of the air storage tank at different internal combustion engine (ICE) speeds.

\subsection{Free Load Condition and Efficiency of Air Motor}

The air motor performance in cases of with and without exhaust from the ICE are presented. This is very important to determine the best position working area and the efficiency of our HPPS. In this case, the air motor ran at the free load condition with and without exhaust from the ICE. The value of the load cell was 0 . The ICE and compressor were run at the sweet spot condition, with an ICE speed of $3800 \mathrm{rpm}$. The exhaust pressure was $27 \mathrm{Psi}$, and the temperature was approximately $350{ }^{\circ} \mathrm{C}$. Following Figure 8 , at the free load condition and outlet of the air tank pressure was lower than 4 bar, the air motor speed rose rapidly from 0 to approximately $2200 \mathrm{rpm}$ without the exhaust condition and from 0 to $2500 \mathrm{rpm}$ with the exhaust condition, when the outlet air tank pressure was increased from 0 to 4 bar. After that, the air motor speed increased from approximately 2200 to $2750 \mathrm{rpm}$ without the exhaust and from approximately 2500 to $2900 \mathrm{rpm}$ in the exhaust condition, when the outlet air tank pressure was raised from 4 to 8 bar.

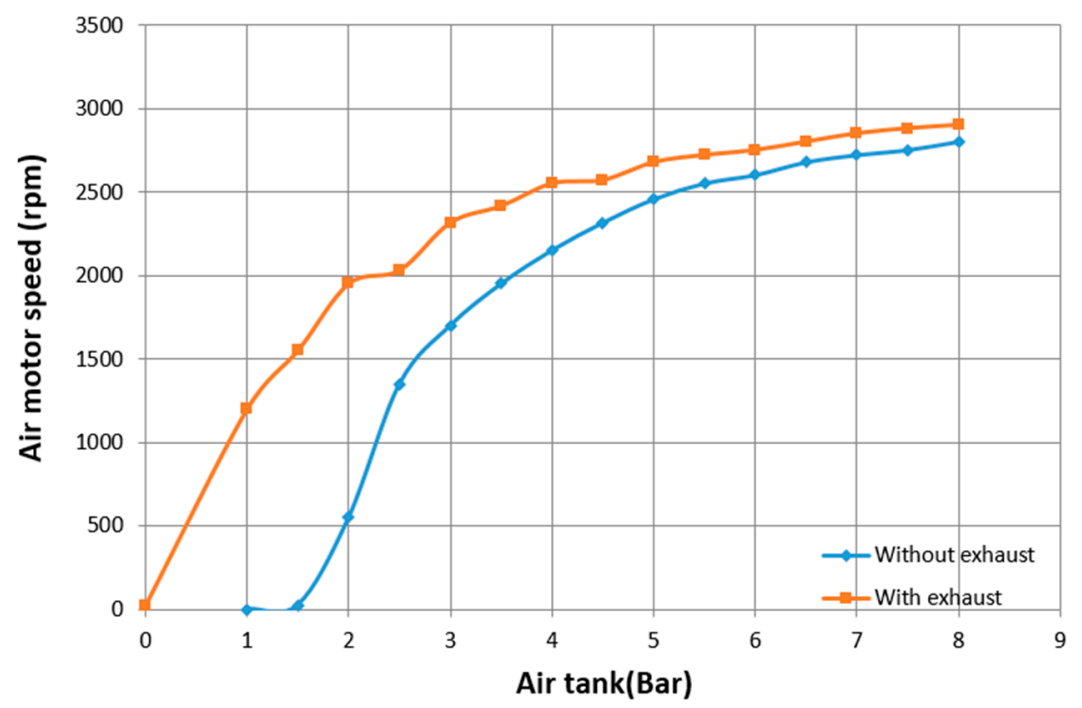

Figure 8. Relationship between air motor speed and inlet pressure in case of with and without exhaust at the free load condition. 
In this test, we measured the efficiency of the air motor under two conditions for the inlet air motor, with and without exhaust from the ICE. In Figure 9, the lower line chart shows the efficiency of the air motor without the exhaust inlet condition, and the higher line chart measures the efficiency of the air motor with exhaust at the inlet condition. With the exhaust at a high temperature and pressure for the inlet condition, the efficiency of the air motor increased to approximately $30 \%$ at a pressure lower than 4 bar for the outlet air tank. Without the exhaust at the inlet condition, the efficiency of air motor dropped rapidly from approximately $38 \%$ at 4 bar of the outlet air tank pressure, to $0 \%$ at $1.5 \mathrm{bar}$ of the outlet air tank pressure. With the exhaust at the inlet condition, the efficiency of the air motor reduced significantly from approximately $62 \%$ at 4 bar of outlet air tank pressure, to $0 \%$ at 0 bar of outlet air tank pressure. From 4 to 8 bar, in the no-exhaust condition, the efficiency of the air motor increased slightly from $38 \%$ to $48 \%$. However, in the exhaust condition, the efficiency of the air motor rose considerably from $62 \%$ to $72 \%$.

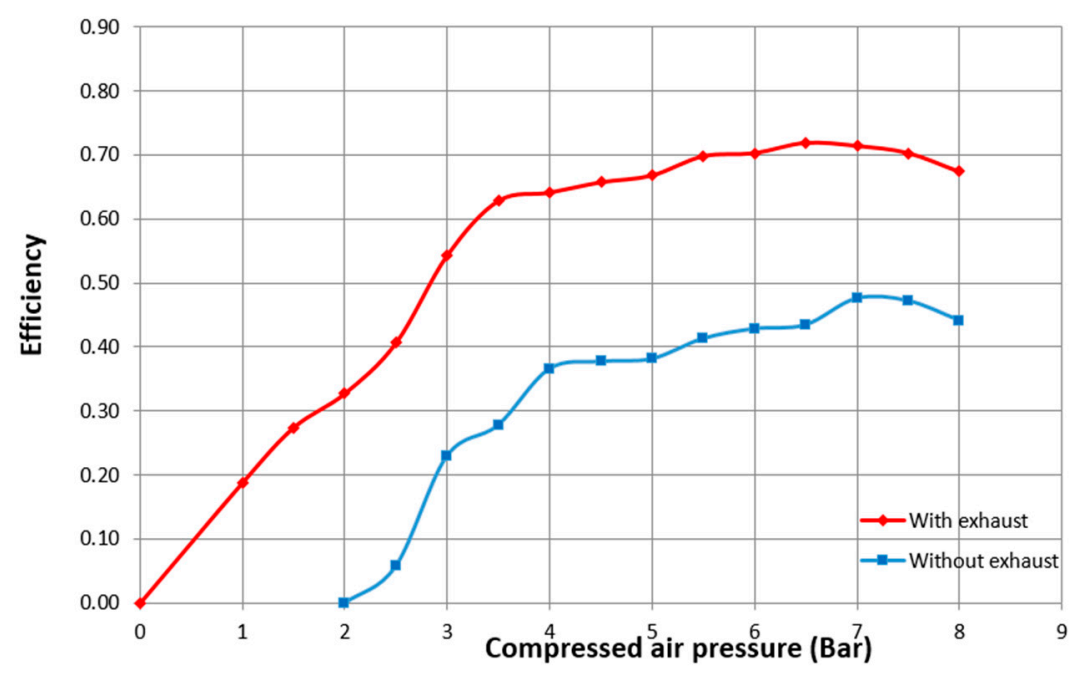

Figure 9. Relationship between efficiency of air motor and inlet pressure for the with and without exhaust cases.

\subsection{Driving Cycle}

This study applies the emissions standards of Economic Commission for Europe (ECE 40). According to the ECE 40 driving cycle requirement, we must control the electric valve at the air tank outlet and control the brake power to follow the outlet of the system. The value of the electric valve is shown in Figure 10. Figure 11 depicts the experimental results of our HPPS when it ran based on the ECE 40 standard. Our HPPS cycles can follow the driving cycle closely. There are some minor errors that occurred with the HPPS speed; this is because the response of the electric valve at the air tank outlet was not fast enough. 


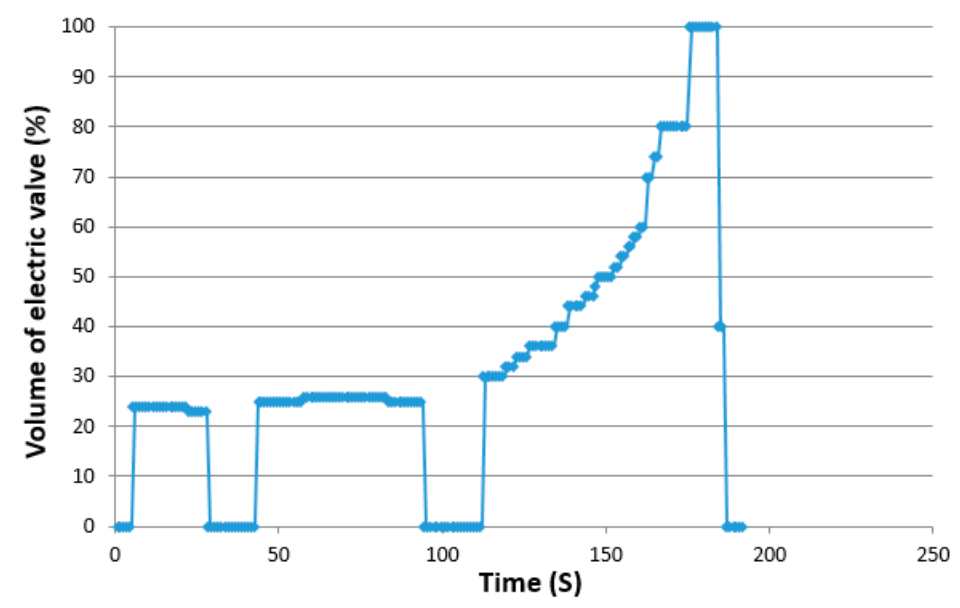

Figure 10. Relationship between the volume of the electric valve and driving time of the emissions standards of Economic Commission for Europe (ECE 40).

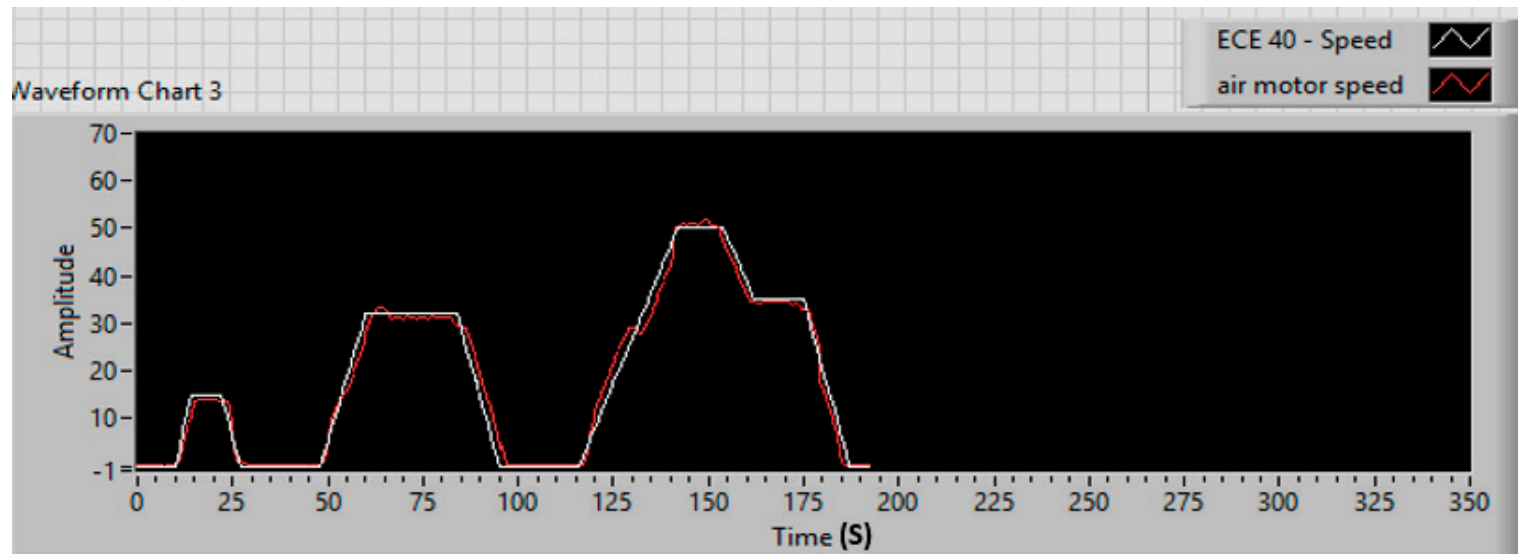

Figure 11. Experimental results of HPPS driving cycle.

\section{Discussion}

\subsection{HPPS Performance}

Based on Figures 4-6, we compared three specifications of the HPPS performance at different ICE speeds. The specifications were fuel consumption, ICE heat efficiency, and compressor efficiency. Base on this comparison, we determined the best working area for the HPPS with high ICE and compressor efficiency, and low fuel consumption. The relationship between the ICE speed, fuel consumption, ICE efficiency, and compressor efficiency is illustrated in Figure 12.

Figure 12 depicts that when the ICE speed was in the range of 3500-4000 rpm, the ICE and compressor demonstrated the best performance in relationship with each other. At ICE speeds $<3500 \mathrm{rpm}$, the system performance reduced as a result of the decreased ICE heat efficiency, compressor efficiency, and increased fuel consumption. At ICE speeds $>4000 \mathrm{rpm}$, the compressor efficiency reduced slightly. Additionally, the ICE efficiency decreased and fuel consumption increased. Therefore, the ICE and compressor did not demonstrate a good performance in relationship with each other. Hence, to obtain the best performance of the HPPS, we need to determine the best position for air motor performance. As can be seen in Figure 9, when the pressure of the compressed air flow was in the range of 6-8 bar, the air motor had the highest efficiency for both cases, with or without exhaust form ICE. 


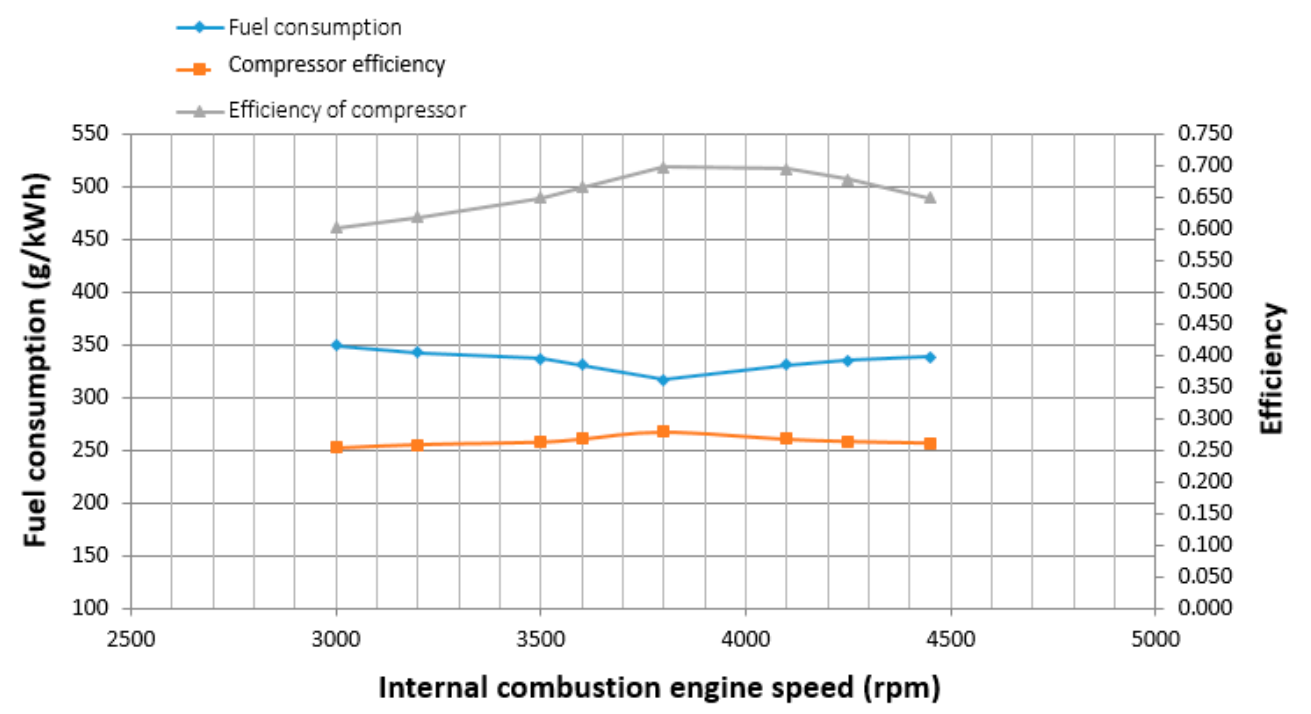

Figure 12. Relationship between the ICE speed, fuel consumption, ICE efficiency, and compressor efficiency.

\subsection{HPPS Efficiency}

From Equation (13), the integral efficiency can be calculated as:

$$
\eta_{t-H P P S} W=\mathrm{Q}_{3} \eta \Leftrightarrow \eta_{t-H P P S} W=\left(\eta_{t} \eta_{C} W+\eta_{\text {exhaust }} W\right) \eta,
$$

where, the best working area of HPPS (Figure 12), $\eta$ (air motor efficiency) is $0.719 ; \eta_{t}$ (ICE efficiency) is $0.28 ; \eta_{C}$ (compressor efficiency) is 0.7 .

According to Ref. [28], the exhaust heat loss can be determined to be approximately $45 \%$ of the total net power. Substitute the values of $\eta, \eta_{t}, \eta_{C}$, and $\eta_{\text {exhaust }}$ in Equation (13):

$$
\eta_{t-H P P S}=\left(\eta_{t} \eta_{C}+\eta_{\text {exhaust }}\right) \eta=(0.28 * 0.7+0.45) * 0.72 \approx 0.465
$$

Based on the experimental results of the ICE efficiency in Figure 5, ICE fuel consumption in Figure 4, compressor efficiency in Figure 6, air motor efficiency in Figure 9, and Ref. [24], we determined the integral efficiency of the HPPS. The system was run at five different ICE speeds $(3000,3250,3600$, 3800 , and $4250 \mathrm{rpm}$ ).

When the ICE is running, compressed air is created and charged into the storage air tank. In case of the cross-section area set at the best position [24], the control electric valve was used to control the pressure and flow rate of the air tank outlet. Then, this air mixes with the exhaust from the ICE. For different ICE speeds, the HPPS will have different stable operations for the air motor. Based on this, the input and output powers of the HPPS were measured, which are summarized in Table 1.

By applying Equation (14), we obtained the efficiency of the HPPS. The experimental result of the HPPS integral efficiency is shown in Figure 13. 
Table 1. Input and output specifications of HPPS.

\begin{tabular}{|c|c|c|c|c|}
\hline ICE Speed (rpm) & Number of Tests & $\begin{array}{c}\text { Air Motor Speed } \\
(\mathrm{rpm})\end{array}$ & $\begin{array}{l}\text { Air Motor Torque } \\
(\mathbf{N m})\end{array}$ & $\begin{array}{l}\text { Fuel Consumption } \\
\text { of ICE (mL/min) }\end{array}$ \\
\hline \multirow{5}{*}{3000} & 1 & 1375 & 9.25 & 12.46 \\
\hline & 2 & 1300 & 9.20 & 12.41 \\
\hline & 3 & 1305 & 9.00 & 12.72 \\
\hline & 4 & 1351 & 9.30 & 12.15 \\
\hline & 5 & 1328 & 9.22 & 12.35 \\
\hline \multirow{5}{*}{3250} & 1 & 1545 & 11.00 & 13.01 \\
\hline & 2 & 1573 & 10.85 & 12.86 \\
\hline & 3 & 1515 & 10.90 & 12.96 \\
\hline & 4 & 1525 & 11.01 & 13.25 \\
\hline & 5 & 1539 & 11.10 & 13.15 \\
\hline \multirow{5}{*}{3600} & 1 & 1765 & 16.25 & 14.63 \\
\hline & 2 & 1800 & 16.10 & 14.61 \\
\hline & 3 & 1805 & 16.15 & 14.51 \\
\hline & 4 & 1750 & 16.30 & 14.86 \\
\hline & 5 & 1755 & 16.31 & 14.76 \\
\hline \multirow{5}{*}{3800} & 1 & 1885 & 16.75 & 14.79 \\
\hline & 2 & 1851 & 16.35 & 15.00 \\
\hline & 3 & 1825 & 16.80 & 14.50 \\
\hline & 4 & 1856 & 16.55 & 15.00 \\
\hline & 5 & 1871 & 16.50 & 14.90 \\
\hline \multirow{5}{*}{4250} & 1 & 1975 & 17.00 & 18.10 \\
\hline & 2 & 2000 & 16.85 & 18.36 \\
\hline & 3 & 2001 & 17.01 & 17.95 \\
\hline & 4 & 1951 & 17.20 & 17.87 \\
\hline & 5 & 1985 & 16.80 & 18.24 \\
\hline
\end{tabular}

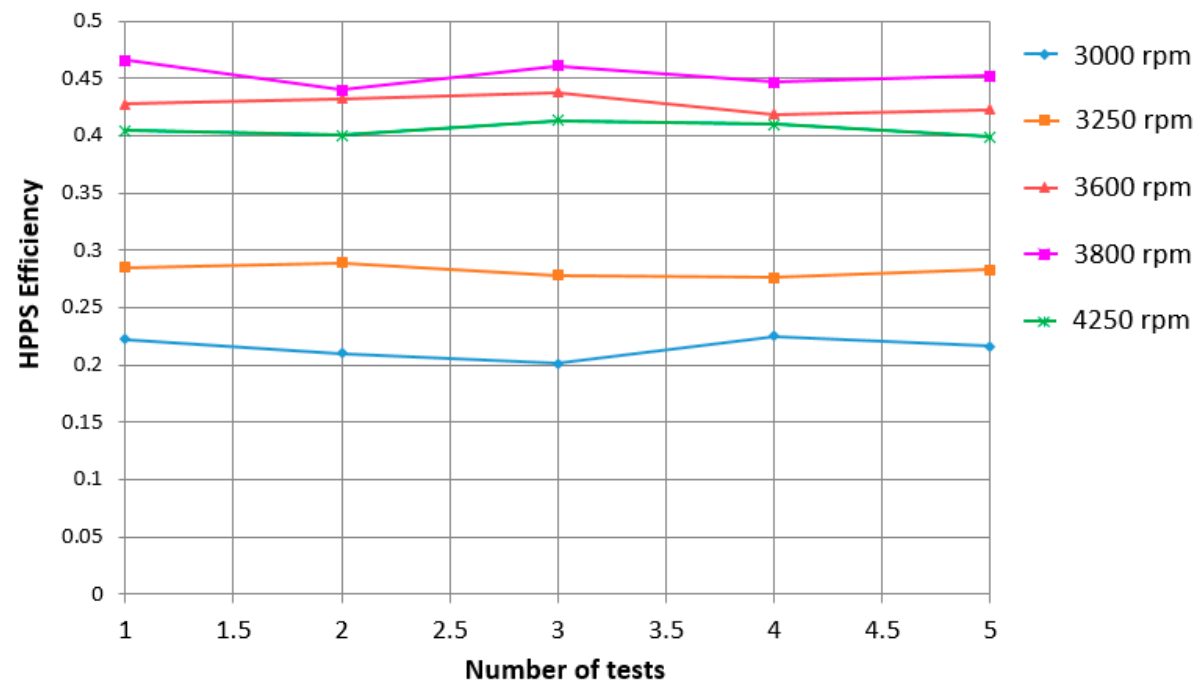

Figure 13. HPPS integral efficiency. 
Figure 13 depicts that the HPPS integral efficiency was different for different ICE speeds. As can be seen in Figure 13, low speeds for the ICE were 3000 and $3250 \mathrm{rpm}$. The system's integral efficiency was about 0.215 at $3000 \mathrm{rpm}$, and about 0.282 at $3250 \mathrm{rpm}$. At this position, based on Figures 5 and 6 , the ICE efficiency was about 0.254 at $3000 \mathrm{rpm}$, and 0.26 at $3250 \mathrm{rpm}$. Additionally, the compressor efficiency was about 0.602 at $3000 \mathrm{rpm}$, and about 0.62 at $3250 \mathrm{rpm}$. Therefore, the compressed air in the tank has a much lower efficiency in comparison with the ICE efficiency. At low ICE speeds, the HPPS operated in a stable condition at low pressure, with low outlet torque and low air motor speed, as summarized in Table 1. This is because of the low pressure of the outlet merger pipe, which was about 3.8 bars at $3000 \mathrm{rpm}$, and about 4.5 bars at $3250 \mathrm{rpm}$.

Our HPPS had the highest efficiency at an ICE speed of about $3800 \mathrm{rpm}$, which averages to about $45.3 \%$. The stable operation of the HPPS was observed at about 7 bars of the outlet merger pipe. Table 1 lists the high outlet torque and high speed of the air motor. At ICE speeds of around $3800 \mathrm{rpm}$, such as 3600 and $4250 \mathrm{rpm}$, the HPPS had a high efficiency. However, this efficiency was still lesser than that at an ICE speed of $3800 \mathrm{rpm}$. This is because of the low efficiency of the ICE and compressor, and high fuel consumption.

\section{Conclusions}

In this study, the experimental performance of our HPPS was analyzed and evaluated. The performance of the HPPS was optimized to the best working area. At this position, the HPPS performance in terms of fuel consumption was lowest, and power at the air motor outlet was highest. The comparison of different HPPS performances demonstrates the role of system operation conditions in system integral efficiency. This study determined the best performance area of the HPPS. At this position, the system integral efficiency was $45 \%$ with a fuel consumption conservation of $38 \%$.

Author Contributions: Conceptualization, D.D.N.; methodology, D.D.N.; software, D.D.N.; validation, P.-T.C., D.D.N. and K.D.H.; formal analysis, D.D.N.; investigation, D.D.N.; resources, C.-J.Y.; data curation, D.D.N.; writing—original draft preparation, P.-T.C. and C.-J.Y.; writing—review and editing, P.-T.C. and C.-J.Y.; visualization, D.D.N.; supervision, C.-J.Y. and K.D.H.

Funding: This research received no external funding.

Acknowledgments: This manuscript was edited by Editage.

Conflicts of Interest: The authors declare no conflict of interest.

\section{References}

1. Chen, P.T.; Shen, D.J.; Yang, C.J.; Huang, K.D. Development of a hybrid electric motorcycle that accords energy efficiency and controllability via inverse differential gear and power mode switching control. Appl. Sci. 2019, 9, 1787. [CrossRef]

2. Chen, P.T.; Yang, F.H.; Gao, H.M.; Huang, K.D. Moderate energy for charging Li-ion batteries determined by first-principles calculations. Batter. Supercaps 2018, 1, 209-214. [CrossRef]

3. Chen, P.T.; Yang, F.H.; Cao, Z.T.; Jhang, J.M.; Gao, H.M.; Yang, M.H.; Huang, K.D. Reviving aged Lithium-ion batteries and prolonging their cycle life by sinusoidal waveform charging strategy. Batter. Supercaps 2019. [CrossRef]

4. Chen, P.T.; Pai, P.H.; Yang, C.J.; Huang, K.D. Development of transmission systems for parallel hybrid electric vehicles. Appl. Sci. 2019, 9, 1538. [CrossRef]

5. Huang, K.D.; Thangavel, S.; Cheng, W.F.; Lin, C.; Chen, P.T. Computational fluid dynamics approach for performance prediction in a zinc-air fuel cell. Energies 2018, 11, 2185. [CrossRef]

6. Thangavel, S.; Chen, P.T.; Cheng, W.F.; Yan, W.M.; Huang, K.D. Optimization of the electrolyte parameters and components in zinc particle fuel cells. Energies 2019, 12, 1090. [CrossRef]

7. Chen, P.T.; Thangavel, S.; Hsu, T.W.; Yang, C.J.; Yung, T.Y.; Yan, W.M.; Huang, K.D. Improved performance of a Zn-air fuel cell by coupling Zn particle fuel and flowing electrolyte. Chem. Phys. Lett. 2019, 728, 160-166. [CrossRef]

8. Freddi, A. Imparare a Progettare (Learning to Design); Pitagora: Bologna, Italy, 2005; ISBN 88-371-1512-1. 
9. Afshari, H.; Peng, Q.; Gu, P. Reducing effects of design uncertainties on product sustainability. Cogent Eng. 2016, 3, 1231388. [CrossRef]

10. Ulrich, K.T.; Eppinger, S.D. Product Design and Development; McGraw-Hill Education: Irwin, CA, USA, 2004; ISBN 13-978-0073404776.

11. Piancastelli, L.; Frizziero, L.; Donnici, G. The common-rail fuel injection technique in turbocharged di-diesel-engines for aircraft applications. J. Eng. Appl. Sci. 2014, 9, 2493-2499.

12. Piancastelli, L.; Frizziero, L. Supercharging systems in small aircraft diesel common rail engines derived from the automotive field. J. Eng. Appl. Sci. 2015, 10, 20-26.

13. Dimitrova, Z.; Maréchal, F. Gasoline hybrid pneumatic engine for efficient vehicle powertrain. Appl. Energy 2015, 151, 168-177. [CrossRef]

14. Broderick, J.K. Combined Internal Combustion and Compressed Air Engine. U.S. Patent US1013528A, 2 January 1912.

15. Ochel, W.; Beyermann, O.; Gehrmann, F. Multicylinder 4-Stroke Cycle Diesel Engine and Compressor. U.S. Patent US2676752A, 27 April 1954.

16. Brown, R. Compressed Air Engine. U.S. Patent US3765180A, 16 October 1973.

17. Ueno, T. Convertible Engine-Air Compressor Apparatus for Driving a Vehicle. U.S. Patent US3963379A, 15 June 1976.

18. Moyer, D.F. Hybrid Internal Combustion Engine. U.S. Patent US5695430A, 9 December 1997.

19. Shi, Y.; Li, F.; Cai, M.; Yu, Q. Literature review: Present state and future trends of air-powered vehicles. J. Renew. Sustain. Energy 2016, 8, 025704. [CrossRef]

20. Fang, Y.; Li, D.; Fan, Z.; Xu, H.; Wang, L.; Yu, X. Study on pneumatic-fuel hybrid system based on waste heat recovery from cooling water of internal combustion engine. Sci. China Technol. Sci. 2013, 56, 3070-3080. [CrossRef]

21. Trajkovic, S.; Tunestal, P.; Johansson, B. Simulation of a Pneumatic Hybrid Powertrain with VVT in GTPower and Comparison with Experimental Data 2009-01-1323. SAE Tech. Pap. 2009. [CrossRef]

22. A Hybrid Pneumatic Driveline for Heavy Duty Vehicles. Available online: Harris.com (accessed on 10 April 2019).

23. Huang, K.D.; Quang, K.V.; Tseng, K.-T. Experimental study of exhaust-gas energy recycling efficiency of hybrid pneumatic power system. Int. J. Energy Res. 2009, 33, 931-942. [CrossRef]

24. Huang, K.D.; Nguyen, H.N.; Quang, K.V. Validation of a Dynamic Model of a Hybrid Pneumatic Power System 09PFL-0282. SAE Int. 2009. [CrossRef]

25. Huang, K.D.; Quang, K.V. Energy merger pipe optimization of hybrid pneumatic power system by using CFD. Int. J. Green Energy 2010, 7, 310-325. [CrossRef]

26. LabVIEW. Available online: http://www.ni.com/zh-tw.html (accessed on 10 April 2019).

27. Pulkrabek, W.W. Engineering Fundamentals of the Internal Combustion Engine; Pearson Education Inc.: Saddle River, NJ, USA, 2004; ISBN 10-0131405705.

28. Rajoo, S.; Romagnoli, A.; Martinez-Botas, R.; Pesiridis, A.; Copeland, C.; Bin Mamat, A.M.I. Automotive Exhaust Waste Heat Recovery Technologies; Nova Science publishers: New York, NY, USA, 2014. [CrossRef]

(C) 2019 by the authors. Licensee MDPI, Basel, Switzerland. This article is an open access article distributed under the terms and conditions of the Creative Commons Attribution (CC BY) license (http://creativecommons.org/licenses/by/4.0/). 